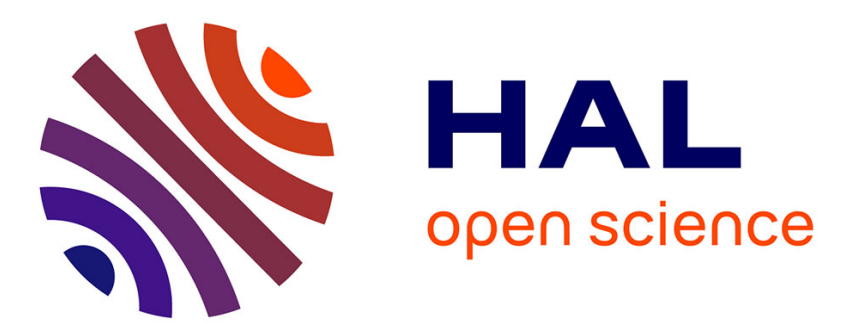

\title{
A game theoretic model for generation capacity adequacy in electricity markets: A comparison between investment incentive mechanisms
}

Haikel Khalfallah

\section{- To cite this version:}

Haikel Khalfallah. A game theoretic model for generation capacity adequacy in electricity markets: A comparison between investment incentive mechanisms. 2009. halshs-00371842

\section{HAL Id: halshs-00371842 \\ https://shs.hal.science/halshs-00371842}

Submitted on 30 Mar 2009

HAL is a multi-disciplinary open access archive for the deposit and dissemination of scientific research documents, whether they are published or not. The documents may come from teaching and research institutions in France or abroad, or from public or private research centers.
L'archive ouverte pluridisciplinaire HAL, est destinée au dépôt et à la diffusion de documents scientifiques de niveau recherche, publiés ou non, émanant des établissements d'enseignement et de recherche français ou étrangers, des laboratoires publics ou privés. 
W.P. 09-05

\section{A game theoretic model for generation capacity adequacy in electricity markets: A comparison between investment incentive mechanisms}

\section{Khalfallah Mohamed Haikel}


A game theoretic model for generation capacity adequacy in electricity markets:

\title{
A comparison between investment incentive mechanisms
}

Khalfallah Mohamed Haikel

$\underline{\text { Khalfallah@gate.cnrs.fr }}$

\begin{abstract}
In this paper we study the problem of long-term capacity adequacy in electricity markets. We implement a dynamic model in which operators compete for investment and electricity production under imperfect Cournot competition. The main aim of this work is to compare three investment incentive mechanisms: reliability options, forward capacity market - which are both market-based - and capacity payments. Apart from the oligopoly case, we also analyze collusion and monopoly cases. Stochastic dynamic programming is used to deal with the stochastic environment of the market (future demand) and mixed complementarity problem formulation is employed to find a solution to this game. The main finding of this study is that market-based mechanisms would be the most cost-efficient mechanism for assuring long-term system adequacy and encouraging earlier and adequate new investments in the system. Moreover, generators would exert market power when introducing capacity payments. Finally, compared with a Cournot oligopoly, collusion and monopolistic situations lead to more installed capacities with market-based mechanisms and increase end-users' payments.
\end{abstract}

Keywords: Electricity markets, capacity adequacy, dynamic programming, Nash-Cournot model, mixed complementarity problem

Classifications JEL: C61, C68, C73, D58, L13, Q41 


\section{Résumé}

Ce papier traite du problème de l'adéquation des capacités de production d'électricité à la demande d'électricité sur le long terme. Sur la base d'un modèle dynamique concurrentiel à la Cournot, nous étudions une situation dans laquelle les producteurs décident à la fois du niveau de production à court terme et de leurs investissements en capacité de génération sur le long terme. L'objectif essentiel de ce travail est de comparer l'efficacité de trois mécanismes d'incitation à l'investissement : les options de fiabilité, le marché de capacité à terme et le paiement de capacité. En plus de la configuration oligopolistique, nous étudions la situation de monopole et celle de la collusion des producteurs. La programmation dynamique stochastique est utilisée afin de mieux prendre en compte l'incertitude sur le marché. La solution du jeu est obtenue en résolvant un problème de complémentarité mixte. Les résultats montrent que l'implémentation du mécanisme des options de fiabilités ou celui du marché des capacités à terme est efficace en terme de coût de production et qu'elle encourage les producteurs à effectuer des investissements adéquats pour répondre efficacement à l'évolution incertaine de la demande future. Par ailleurs, l'exercice du pouvoir de marché est atténué avec ces deux mécanismes contrairement à ce qui est obtenu pour le mécanisme de paiement de capacités. Finalement, le niveau des capacités installées augmentent avec le mécanisme des options de fiabilités et avec celui du marché des capacités à terme quand on passe d'une situation d'oligopole à une situation de collusion ou de monopole. Ce résultat se traduit par une augmentation du prix payé par le consommateur final.

Mots clefs: marché d'électricité, adéquation des capacités de génération, programmation dynamique, problème de complémentarité mixte, modèle Nash-Cournot

Classifications JEL: C61, C68, C73, D58, L13, Q41 


\section{Introduction}

Policymakers in many countries agree that competitive wholesale electricity markets do not present adequate incentives to stimulate sufficient investment in new generation capacity. The energy market itself ${ }^{1}$ without any additional mechanism fails to guarantee generation adequacy. These concerns have increased owing to the uncertain growth of electricity demand, price volatility, which makes new investment very risky, and the potential for market power abuse, especially in a peaking period. Some studies suggest that these factors, coupled with serious market design flaws and other circumstances, caused the Californian crisis in the summer of 2000 , viewed as the first failure of deregulation. It was characterized by extraordinarily high spot market prices, the rise of total energy costs at up to ten times the historical level, shortages and subsequent rolling blackouts within the state.

Apart from these factors in the failure of the energy-only market, another real problem which reduces market signals for attracting adequate investment in generation is the 'missing money' problem. In fact, a competitive electricity price cannot, by itself, cover both the operating costs and the capital investment cost required to attract new investment in longlived generation capacity to support a least-cost generation supply portfolio consistent with mandatory reliability criteria. This would induce high and inefficient prices through price manipulations in the market as well as an imbalance between the steadily growing demand for power and the existing generation capacity.

The discussion above illustrates why there are many proponents of designing electricity markets with investment incentive mechanisms, in addition to the spot market, which could be a solution to ensure long-term reliability of electricity markets. Several mechanisms have either been applied or seriously considered at international level. They are classified in two categories. The first one is the non-market-based mechanisms. The most important is the capacity payment mechanism. ${ }^{2}$ It has frequently been used to compensate generators for improving reliability. These payments are important revenue sources for generating units that are scheduled to provide available capacity but would probably not be called to produce electricity and that would not recover investment costs when only receiving energy payments from competitive generation markets. In peak periods, generators are given an additional capacity payment based on their availability (whether they get dispatched or not) or based on generated energy as an addition to the energy market clearing price. The problem with this mechanism is that no commitment is imposed on generators and therefore the level of adequacy cannot be guaranteed. It is also very difficult to find a convincing way of determining the efficient capacity price. Another non-market-based mechanism is the purchase of peaking units by the system operator. This approach is meant to avoid generation units that provide capacity at the margin deciding to leave the market when their revenues are too volatile or when they are insufficient to cover at least their total operating cost. It is,

\footnotetext{
${ }^{1}$ Known as the 'energy-only market', which requires the elimination of any price cap, it allows full participation of demand and leaves each market agent to experience fully the volatility of market prices.

${ }^{2}$ It has been implemented in the UK (before the new trading arrangements (NETA)), Italy, Spain and several Latin American countries.
} 
however, strongly interventionist and may interfere with the proper functioning of the market (see Arriaga (2001)).

The second category is the market-based mechanisms. In a forward capacity market model, generation adequacy would be ensured by giving consumers the opportunity to ensure ex ante the capacities' availability from generators. Every year, end-users can contract enough firm generation capacity above their peak load to cover their expected peak load plus a regulated margin. This leads to the creation of a forward capacity market, in addition to the energy market, that allows trading generators' capacities. The forward capacity markets provide generators with the opportunity to collect extra revenue for their generation capacities and provide incentives for the building of reserves beyond those that meet the short-term needs for ancillary services. They are committed to have the contracted capacity available whenever they are required to produce it, otherwise they pay a penalty charge. Joskow (2007) suggests that when generators are called to offer their contracted capacity in the spot market, they are also required to refund the consumers any infra-marginal rent corresponding to the difference between the spot price and the marginal cost of a peaking unit of reference. In other words, energy prices are capped by a regulated reference price.

The second market-based mechanism is the reliability options scheme. ${ }^{3}$ It has the same objective as the forward capacity market, in which the availability of generation has to be bought ex ante, but it differs in its organisation. Here, the system operator (SO) proposes a system of options to protect electricity buyers against excessive prices in the spot market. Energy producers are rewarded for the insurance they provide and punished when they fail to supply the energy for which they have contracted. The options are marketed by the SO through yearly uniform price auctions. The SO determines in advance the strike price for the auction, which acts as a price cap for demand, and the time horizon during which the generator is required to generate the committed energy at any time. The SO will exercise his/her option whenever the energy price exceeds the strike price. Generators submit one or several bids to the auction, expressing quantity (the committed energy) and price (the required premium). Finally, the market is cleared as a simple auction and all of the accepted bids receive the premium that was solicited by the marginal bid. The call is represented as follows: consumers pay a premium to acquire the right to buy energy at the exercise price rather than the spot price and generators receive the premium for abandoning the right to sell at the spot price and for committing to sell at the exercise price whenever consumers exercise the option. On the one hand, this method stabilizes the income of generators, who exchange an uncertain and volatile income (the energy price) for a certain one (the premium from the auction); on the other hand, it represents a market-based mechanism to hedge demand against the occurrence of high market prices (since the energy price is capped by the strike price).

The intention of the market-based mechanisms is to guarantee a regulated generation adequacy level for the system by defining specific commitment of generation and assuring that generators will be available when the system needs them because of scarcity of supply. They also give generators the opportunity to collect extra stable income in the market,

\footnotetext{
${ }^{3}$ Not tried in practice.
} 
enabling them to cover both the operating costs and the capital investment cost required for new investment.

In this paper, we try to compare three investment incentive mechanisms, capacity payment, forward capacity market and reliability options in terms of long-term capacity adequacy in an uncertain environment, particularly since, to our knowledge, there has been almost no previous research on how the mechanisms can deal with this problem in the long term. In other words, do such instruments solve the problem of supply adequacy and at what cost? By long-term system adequacy we mean the existence of enough installed available capacity of the appropriate characteristics to meet the estimated peak demand with efficient costs. In the light of our assumptions about the structure, we also show why the energy-only market would not give good signals for new capacity additions, and why the implementation of an additional incentive mechanism is needed to guarantee the availability of all generators, to attract new investments and to reduce market power.

In the literature, the problem of long-term system reliability has been largely studied in qualitative terms. Arriaga [2001] studies the different mechanisms discussed above and indicates the weak and strong points of each one. Similar approaches to the reliability options scheme proposed by Vazquez and colleagues [2002] have also been described by Oren [2004] and Papalexopoulos [2004]. Joskow [2007] discusses three real problems with competitive wholesale electricity markets that reduce the attractiveness of investments in new generation capacity: the lower level of competitive electricity prices (the 'missing money' problem), their volatility and the regulatory uncertainty in market rules and market institutions. He suggests that the introduction of a forward capacity market, in addition to the spot market, would be a solution to attract adequate investment in generation capacity. Doorman [2003] proposes a capacity subscription model where consumers have the freedom to choose their level of reliability through the amount of maximum capacity to which they subscribe.

There are, however, a few works that attempt to model the quantitative effects of those market designs. For instance, a system dynamics model shows in Ford [1999] that, first, without incentives, construction cycles would occur frequently and the industry would face repeated periods of undersupply and oversupply, and second, the introduction of a constant capacity payment could diminish considerably the occurrence of these cycles. The model presented in Botterud [2003] looks at the question of long-term generation capacity adequacy in restructured and competitive power systems where future demand is represented as a stochastic process. The results clearly show that a dynamic capacity payment, where capacity price is endogenous to the reliability in the market, is more likely to maintain an adequate level of installed capacity if demand grows faster or slower than expected. The model presented in Botterud and colleagues [2005] calculates optimal investment strategies under both centralized social welfare and decentralized profit objectives. It is shown, first, that a price cap below the value of lost load or monopolistic investment conditions will contribute to postponing investment decisions further, and second, that a capacity payment will help trigger earlier investments, but can also result in too much investment in peaking units. De Vries [2004] develops a simulation model for the Dutch power system. The model is used to analyse the effect of several of the capacity mechanisms. The main conclusion is that 
mechanisms with a regulated volume of generation capacity are more robust than those that use economic incentives for stimulating investments. It is therefore argued that capacity obligations are the most attractive.

The work presented in this paper adds to the literature on modelling the long-term effect of investment incentive mechanisms. Differently from the literature where imperfect competition is disregarded, we apply the Nash-Cournot model of oligopoly behaviour to formulate a three-stage model that may characterise three decisions in an imperfect competitive regime: expansion planning, generation decisions and commitment decisions (commitment to produce when applying the market-based mechanisms).

In the energy area, a considerable volume of literature deals with imperfect competition. Only investment and production decisions, however, are considered. Pineau and Murto [2003] use a sample-path adapted open-loop information structure ${ }^{4}$ to present a dynamic stochastic oligopoly model that describes production and investment in a deregulated electricity market with uncertainty of future demand. Variational inequality and mixed complementarity problem formulations are employed to find a solution. Their model offers a helpful description of the dynamic production-investment problem. Gilotte and colleagues [2005] extend their paper by increasing uncertainty and including the possibility of the phasing-out of existing capacities. In addition, other contributions (Von der Fehr and Harbord [1997], Murphy and Smeers [2005]) study investments in new generation capacities with theoretical two-stage oligopoly models, but the description of the electricity market is essentially static. Ventosa and colleagues [2002], from the mixed complementarity problem and the mathematical program with equilibrium constraints formulations, developed a Cournot model and a Stackelberg model of expansion planning where future demand is certain. Chuang and colleagues [2003] use a Cournot model that analyses the generation expansion planning in a competitive electricity industry. Based on the iterative search procedure, results show a greater industry expansion and system reliability under Cournot competition than under centralized expansion planning. Contrary to this literature, a mechanism stage is added in our work in order to study how the investment and production could change if an incentive mechanism is implemented.

Mixed complementarity problem formulations are largely used to find a solution to a Nash-Cournot model (Ventosa et al. [2002], Gabriel et al. [2005]). It takes advantage of the competitors' simultaneous decisions in a Nash-Cournot model and its complementarity structure. In our study, we have two continuous decisions (commitment and production) and one discrete decision (investment). Each sub-model at the continuous decision stage is described as a mixed complementarity problem in order to represent the equilibrium properly. A sequential Nash-Cournot solution, however, is used to find the optimal investment choice.

Contrary to the literature discussed above, a closed-loop solution ${ }^{5}$ is used in this paper to represent the interaction between all competitors' decisions. The method suggests that the

\footnotetext{
${ }^{4}$ The method supposes that all decisions are simultaneous.

${ }^{5}$ A good comparison between the open-loop and closed-loop solutions in electricity markets is proposed in Murphy and Smeers [2002].
} 
three decisions are not decided at the same time. Investment decisions are made in the first stage, commitment decisions in the second stage and operating decisions in the third stage. The game is then truly a three-stage game where competition takes place in three steps. The generators play against each other when making investments, knowing how they will play against each other when participating in the mechanism and when operating their plants. This is also the case in the mechanism stage; they know their optimal future production decisions depend on their actual commitment decisions. Owing to the presence of uncertainty of future demand, stochastic dynamic programming is used to solve the overall problem. ${ }^{6}$

The main finding of this study is that market-based mechanisms would be the most cost-efficient way of ensuring long-term system adequacy and encouraging earlier and adequate new investments in the system. Moreover, generators would exert market power with non-market based mechanisms. Finally, compared with Cournot competition, cartel and monopolistic situations lead to more installed capacities with market-based mechanisms and increasing end-user payments.

The paper is organized as follows. Section 2 presents the assumptions used in our models. Section 3 outlines the proposed dynamic model formulations. Section 4 presents the empirical analysis and the results from the application of our model to the French electricity sector. Section 5 summarizes and concludes.

\section{Modeling Assumptions}

In this section, we describe the different assumptions made to formulate our NashCournot models of oligopoly behavior.

Four models are developed to represent each investment incentive mechanism in an uncertain environment. The general assumptions apply to all the models, but there are specific assumptions that describe the functioning of each mechanism.

\subsection{General assumptions}

All the models consider a hyperannual scope divided into different time segments: periods and seasons. Periods correspond to years and seasons correspond to the following demand levels: off peak, shoulder and peak seasons.

We also consider the uncertainty of future demand. We assume that this uncertainty may be represented by a finite set of scenarios. Therefore, the stochastic evolution of the demand can be modeled by means of a Markov chain. Each branch represents a different realization of demand with its associated probability (see Figure 1).

\footnotetext{
${ }^{6}$ Dynamic programming is an approach developed to solve sequential, or multi-stage, decision problems. It divides the problem to be solved into a number of sub-problems and then solves each in such a way that the overall solution is optimal to the original problem.
} 


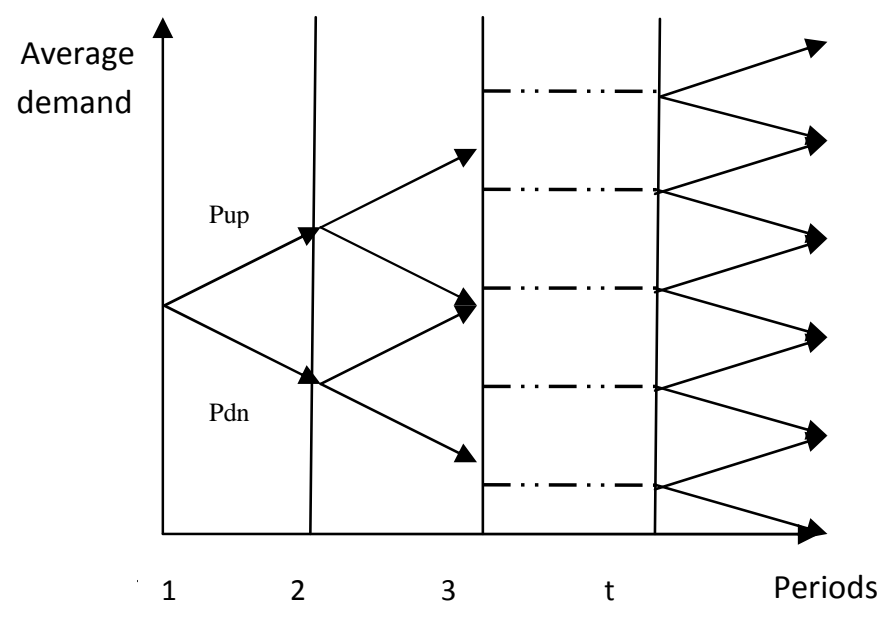

Figure 1. Tree description of a discrete Markov chain for uncertain demand

In the models, three firms compete in a Nash-Cournot manner. An important assumption of the models is that each firm is specialized in a single technology type (baseload, shoulder or peak technology). At each period, they decide the new capacity to be added into the system and at each season they choose simultaneously the operation decision. When introducing the market-based incentive mechanism, they also have to choose the commitment decision (commitment to produce in the future period). The investment decision is a discrete variable which takes into account the construction delay that differs according to the technology type. In order to reduce the investment scenarios, we suppose also that if an expansion decision is made, additional investments cannot be made until the ongoing construction period is finalized. Commitment and generation decisions, however, are continuous and constrained by the generation capacity level.

\section{$\underline{2.2 \text { Specific assumptions }}$}

We distinguish between three groups of market designs: market-based incentive mechanisms, non-market-based incentive mechanisms and the benchmark case.

\section{Market-based incentive mechanism: reliability options}

Besides investment and operating decisions, firms decide in an organized auction the committed quantity to be available in the future peak period. The auction is organized one year ahead of real time, which corresponds to the peak season of a future period. In this auction, the system operator ( $\mathrm{SO}$ ) purchases the commitment from generators to produce in the future a prescribed quantity of energy (highest expected peak demand). The method is based on the financial call option principle. ${ }^{7}$ The SO sets the strike price. When the electricity

\footnotetext{
${ }^{7}$ A call option is the right (but not the obligation) to buy a stock, bond, commodity or other instrument at a specified price (the strike price) within a specific time period.
} 
price exceeds the strike price, the SO exerts his/her option and commits the generator to produce and to sell their committed energy at the strike price. If a generator is not available to produce, it pays a penalty charge fixed administratively at the time of the auction. Each generator submits one bid to the auction, expressing quantity and price (the required premium). The market is cleared as a simple auction and all of the accepted bids receive the premium that was requested by the marginal bid. The call is represented as follows: the SO on behalf of all consumers pays a premium to acquire the right to buy energy at the exercise price rather than the spot price and generators receive the premium for abandoning the right to sell at the spot price and for committing to sell at the exercise price whenever the SO exercises the option. Consequently, energy producers are rewarded for the insurance they provide and punished when they fail to supply the energy for which they have contracted.

The overall game is represented as follows: at each period, firms choose the new capacity to be added into the system. Since the decision is a discrete variable, we use the sequential Nash-Cournot method to find a solution. We suppose that there is a leader firm (L) which decides first, a second firm (F1) operating as a follower of L and a third firm (F2) as a second follower of L and F1. After deciding the capacity addition, they compete to choose the quantity to be committed in the auction of the mechanism. This decision is a continuous variable and is found from the mixed complementarity problem method (MCP). It is constrained by the expected generating capacity of the firm in a future year. Finally, at each season of the period, operating decisions are made, also constrained by the generating capacity level of the firm and the commitment decision made in the previous year. The game is then truly a repeated three-stage dynamic game where competition takes place in three steps. Therefore, a closed-loop solution is used to represent the interaction between all competitors' decisions. The resolution method is detailed in Section 3.

\section{Market-based incentive mechanism: forward capacity markets}

Similarly to the reliability options design, the main aim of this mechanism is to ensure the ex ante availability of generation. It is, however, organized in another way. The commitment decision here concerns the firm generating capacity and not energy. Thus a capacity market is organized one year ahead of real time and the SO, on behalf of all demand, purchases a prescribed level of firms' generating capacities that can cover the expected future peak load. The capacity market provides generators with the opportunity to collect extra revenue for their generation capacities and provides incentives for the building of reserves beyond those that meet the short-term needs for ancillary services. On the other hand, generators are committed to making available their contracted capacity whenever they are required to produce it, otherwise they pay a predetermined penalty charge.

The capacity market is organized as an auction procedure similar to the first marketbased mechanism. The single difference concerns the strike price. While it is exogenous and fixed administratively in the reliability options scheme, it is uncertain and endogenous in the capacity markets mechanism. In fact, when generators are called to offer their contracted capacity in the spot market, they are also required to refund the consumers any infra-marginal rent (see Joskow [2006] for more details) corresponding to the difference between the spot 
price and the variable cost of a peaking unit of reference. This regulated cost of reference can be considered here as an endogenous strike price.

The overall game is represented as in the first market-based mechanism and described as a repeated three-stage dynamic game where competition takes place in three steps. Moreover, another variant of this mechanism is studied here. Instead of assuming that the capacity price is determined via an auction procedure, we use a specific function that reflects the market's demand for capacity and expresses the relationship between the generator's payment from capacity market and the expected reliability in the system.

\section{Non-market-based incentive mechanism: capacity payments}

With this design, generators are given in peak seasons an additional capacity payment based on their availability, whether they get dispatched or not. No obligation to serve is imposed on them and the additional payment given by the fixed capacity payment compensates generators for improving reliability and persuades them to invest in the system.

Here, the game is represented by a two-stage dynamic model: firms decide only the new capacity to be added into the system and operating decisions. The solution at each stage is found by the same method used for modelling the market-based mechanisms.

\section{The benchmark case: energy-only market}

Similarly to the capacity payment mechanism, only investment and operating decisions are made by generators. Furthermore, no additional instruments are introduced here and generators' revenues are only provided by their sales in the spot market.

\section{The Dynamic Models}

\subsection{Reliability options model (Model A)}

When introducing the reliability options mechanism, as discussed in Section 2.2, the objective of each firm is to maximize its profit - market and mechanism revenues minus operating costs and investment costs - for the entire period.

The objective function to be maximized is described as follows:

For each firm,

$$
\max _{q_{c, s}^{t}, e_{c}^{t}, u_{c}^{t}} J_{c}=\sum_{t=1}^{16} \beta^{t} \cdot\left\{\sum_{i^{t}} \alpha\left(i^{t}\right) \cdot\left\{\sum_{s=1}^{3} g_{c, s}^{t}\left(q_{c, s}^{t}, Q_{s}^{t}, D_{s}^{t}, E^{t}, i^{t}\right)+z_{c}^{t}\left(e_{c}^{t}, i^{t}\right)-i c_{c}^{t} \cdot K_{c}^{t}\left(i^{t}\right)\right\}\right\}
$$

Subject to

$$
\begin{aligned}
& K_{c}^{t+l t_{c}}\left(\bar{l}^{t}\right)=K_{c}^{t}\left(i^{t}\right)+u_{c}^{t}\left(i^{t}\right) \\
& q_{c, s}^{t}\left(i^{t}\right) \leq K_{c}^{t}\left(i^{t}\right) \cdot L_{S} \\
& Q_{S}^{t}\left(i^{t}\right) \leq D_{S}^{t}\left(i^{t}\right)
\end{aligned}
$$


$e_{c}^{t}\left(i^{t}\right) \leq K_{c}^{t+1}\left(\tilde{l}^{t}\right) \cdot L_{2}$

$\sum_{c} e_{c}^{t}\left(i^{t}\right) \leq E^{t}\left(i^{t}\right)$

The notation is defined as follows:

$\begin{array}{ll}c=1,2,3 & \text { Player (generator) } \\ t=1, \ldots ., 16 & \text { Period (year) } \\ s=1,2,3 & \text { Season (baseload, shoulder and peak respectively) } \\ \beta & \text { Discount factor } \\ l_{c} & \text { Construction delay of generator c's technology } \\ i^{t} & \text { Demand level state at } \mathrm{t} \text { (random variable) } \\ \bar{t}^{t} & \text { Successor state of } i^{t} \text { at } \mathrm{t}+\mathrm{lt} \\ \tilde{l}^{t} & \text { Successor state of } i^{t} \text { at } \mathrm{t}+1 \\ J_{c} & \text { Total expected profit of generator c (€) } \\ g_{c, s}^{t} & \text { Generator's revenue at season s at period } \mathrm{t}(€) \\ z_{c}^{t}\left(e_{c}^{t}, i^{t}\right) & \text { Generator's revenue from market mechanism (€) } \\ \alpha\left(i^{t}\right) & \text { Probability of } i^{t} \\ K_{c}^{t}\left(i^{t}\right) & \text { Capacity of generator c at period t and } i^{t}(\mathrm{MW}) \\ u_{c}^{t}\left(i^{t}\right) & \text { (Decision variable) capacity addition of generator c at period } \mathrm{t} \text { and } i^{t} \\ & \text { (MW) } \\ q_{c, s}^{t}\left(i^{t}\right) & \text { (Decision variable) production of c at season s at period } \mathrm{t} \text { and } i^{t}(\mathrm{MWh)} \\ Q_{s}^{t}\left(i^{t}\right)=\sum_{c} q_{c, s}^{t}\left(i^{t}\right) & \text { Total production for season s at period } \mathrm{t}(\mathrm{MWh}) \\ D_{s}^{t+1}\left(i^{t}\right)=D_{s}^{t}\left(i^{t}\right)+w^{D} & \text { (State variable) demand level for season s at period (MWh) } \\ e_{c}^{t}\left(i^{t}\right) & \text { (Decision variable) quantity committed by c at the mechanism stage at } \\ E^{t}\left(i^{t}\right)=\sum_{c} e_{c}^{t}\left(i^{t}\right) & \text { period } \mathrm{t}(\text { MWh) } \\ i c_{c}^{t} & \text { Total quantity committed at the mechanism stage at period } \mathrm{t}(\mathrm{MWh}) \\ w^{D} & \text { Investment cost of generator c's specific technology at period } \mathrm{t}(€) \\ L_{s} & \text { Long-term uncertainty of demand level (MWh) } \\ & \text { Number of hours in season s }\end{array}$

Specific constraints are omitted here and will be presented later. Constraint (2) shows that the capacity level of $\mathrm{c}$ at period $\mathrm{t}$ is only affected by investment decision made at $t-l t_{c}$ i.e. by taking into account the specific construction delay of technology. Constraints (3) and (4) prevent the firm's production from exceeding its installed capacity and the total quantity produced from exceeding the demand level. Constraints (5) and (6) concern the mechanism stage. The former limits the generators' committed quantity in the auction of the mechanism to its expected installed capacity in the future period. The latter prevents the total committed quantity from exceeding the quantity requested by the system operator.

\section{$\underline{3.1 .1 \text { Solving the model }}$}

Our game is a repeated three-stage dynamic game where competition takes place in three steps. First, at the beginning of each period, firms decide the capacity to be added into the system, $u_{c}^{t}\left(i^{t}\right)$ which is a discrete decision (invest or not invest). The second stage 
concerns the commitment decision, $e_{c}^{t}\left(i^{t}\right)$. This choice is constrained by the expected capacity level of the firm in the future period and thus depends on the investment decision made in $t-l t_{c}+1$. In fact, when offering energy at the auction, firms are ready to commit themselve to be available and to produce at the future peak season, so they limit their offers to their expected capacity level $K_{c}^{t+1}\left(\tilde{l}^{t}\right)$. Finally, at each season of the period, they decide simultaneously their production depending on the demand level in the season and constrained by the capacity level. Moreover, in the peak season, generators have to fulfill their commitment made at the previous period (mechanism stage), so the production at this season is also constrained by $e_{c}^{t-1}\left(i^{t-1}\right)$. This game is repeated annually over the planning period.

Given our game configuration, we use the closed loop information structure to solve the model where the solution is obtained by backward induction. Operating decisions are made on the basis of the observed investment decisions and commitment decisions. Commitment decisions are also chosen on the basis of previous observed investment decisions but with considerations of how operating decisions in the future peak season will be made. Similarly, investments decisions are obtained with considerations of how second and third stage decisions will be made. Except for the difficulty generally encountered in the use of this technique, it is subgame perfect because the associated strategies are Nash equilibrium at each stage of the game, even if there has been a deviation from the equilibrium strategy in an earlier subgame, contrary to the open-loop information structure. We note finally that firms also adapt their investment decisions at each period to those made in the future. Consequently, a stochastic dynamic programming method is used to find all capacity additions for the total planning period. The essence of dynamic programming is Bellman's principle of optimality. ${ }^{8}$

In the following sections, we calculate the Nash-Cournot equilibrium associated with each stage of the game (operating, commitment and investment stages) and, using the backward induction method, we start from the last decision and end with the first one.

\subsubsection{Operating decisions stage}

At each season of the period, firms decide in Nash-Cournot manner the quantity to be produced. We distinguish between two classes of seasons: first, the baseload and shoulder seasons where production level is only constrained by the operating capacity level; second, the peak season where the mechanism is activated and the commitments made at the last period (in the auction of the mechanism) become constraining.

\subsection{2 a Plateau and off-peak seasons}

Generator c's sub-model associated with these seasons is represented as follows:

$$
\max _{q_{c, \bar{s}}^{t}} g_{c, \bar{s}}^{t}=\left(P_{\bar{s}}^{t}\left(q_{c, \bar{s}}^{t}, \bar{q}_{c^{\prime}, \bar{s}}^{t}, D_{\bar{S}}^{t}, i^{t}\right)-C V_{c, \bar{s}}^{t}\left(q_{c, \bar{s}}^{t}, i^{t}\right)\right) \cdot q_{c, \bar{s}}^{t}\left(i^{t}\right)
$$

\footnotetext{
${ }^{8}$ Bellman's principle of optimality states that: 'An optimal policy has the property that, whatever the initial action, the remaining choices constitute an optimal policy with respect to the sub-problem starting at the state that results from the initial action'.
} 
Subject to:

$$
\begin{array}{ll}
q_{c, \bar{s}}^{t}\left(i^{t}\right) \leq K_{c}^{t}\left(i^{t}\right) \cdot L_{\bar{s}} & \left(\alpha_{c, s}^{t}\right) \\
q_{c, \bar{s}}^{t}\left(i^{t}\right)+\bar{q}_{c, \bar{s}}^{t}\left(i^{t}\right) \leq D_{s}^{t}\left(i^{t}\right) & \left(\gamma_{c, s}^{t}\right) \\
q_{c, \bar{s}}^{t}, \alpha_{c, s}^{t}, \gamma_{c, s}^{t} \geq 0 &
\end{array}
$$

Where,

$\bar{s}$

$P_{\bar{S}}^{t}\left(i^{t}\right)=a_{\bar{s}}+b_{\bar{S} \cdot}\left(D_{\bar{S}}^{t}\left(i^{t}\right)-\sum_{c} q_{c, \bar{s}}^{t}\right)$

$C V_{c, \bar{s}}^{t}\left(i^{t}\right)=d_{c, \bar{s}}+r_{c, \bar{s}} \cdot q_{c, \bar{s}}^{t}$

$\bar{q}_{c^{\prime}, \bar{s}}^{t}$

$a_{\bar{S}}, b_{\bar{s}}$

$d_{c, \bar{s}}, r_{c, \bar{s}}$

$\alpha_{c, S}^{t}, \gamma_{c, S}^{t}$
Seasons (plateau, off-peak)

Spot price at season $\bar{s}$ at period $\mathrm{t}$ and $i^{t}(€ / \mathrm{MWh})$

Unitary variable cost of firm c's technology at season $\bar{s}$ at period $\mathrm{t}$ and $i^{t}(€ / \mathrm{MWh}$ )

Total production of generator c's competitors which are assumed fixed (Nash-Cournot assumption) (MWh)

Constant to be estimated from historical data

Constant of variable cost function of $\mathrm{c}$

Dual variables for the constraints

In order to evaluate the possibility of price manipulations by generators, we use a linear function that expresses the relationship between the electricity price and the security of the system represented by $\left(D_{\bar{S}}^{t}\left(i^{t}\right)-\sum_{c} q_{c, \bar{s}}^{t}\right)$, which is the difference between the demand level of the season and the total quantity produced. On the one hand, if there is no shortage in the system $\left(D_{\bar{S}}^{t}\left(i^{t}\right)=\sum_{c} q_{c, \bar{S}}^{t}\right)$, the electricity price is equal to $a_{\bar{s}}$, which is an approximation of the marginal cost of the expensive technology operating at this season. On the other hand, when there are shortages, the electricity price increases: the scarcer the supply is $\left(D_{\bar{S}}^{t}\left(i^{t}\right)-\right.$ $\left.\sum_{c} q_{c, \bar{s}}^{t} \gg 0\right)$, the higher the price is. This price formulation will be used later for all the models studied here. Furthermore, a quadratic function is used to represent the generator's total variable cost.

Each firm maximizes simultaneously its profit from the season s (7) under constraints (8) and (9). The Nash-Cournot equilibrium ${ }^{9}$ is unique since the cost function $C V_{c, \bar{s}}^{t}($.$) is$ strictly convex and continuously differentiable, and the revenue function $P_{\bar{S}}^{t}(.) \cdot q_{c, \bar{s}}^{t}$ is concave. The solution is found by grouping together all generators' first order optimality conditions, so a mixed complementarity problem ${ }^{10}$ is formed. After resolving the model, we find the generator's optimal production decisions of the season, function of installed capacity at the period $q_{c, \bar{s}}^{* t}\left(K_{c}^{t}\left(i^{t}\right)\right)$.

\footnotetext{
${ }^{9}$ The proof of existence of the oligopolistic Nash-Cournot equilibrium is well-established in many papers. See Murphy et al. (1982) or even Friedman (1977).

${ }^{10}$ It solves directly the necessary conditions of the Nash equilibrium. Writing the first order optimality conditions simultaneously for all players results in a mixed complementarity problem. A general purpose complementarity code like MILES can then be used to solve this.
} 


\subsection{2.b Peak season}

In the peak season, as explained in Section 2.2, the mechanism plays and the commitments made at the last period (in the auction of the mechanism) become constraining. The generator's sub-model associated with this season can be defined as:

$$
\begin{gathered}
\max _{q_{c, 3}^{t}, \tilde{q}_{c, 3}^{t}} g_{c, 3}^{t}= \\
S^{t-1}\left(\hat{\imath}^{t}\right) \cdot q_{c, 3}^{t}\left(i^{t}\right)+P_{3}^{t}\left(Q_{3}^{t}, D_{3}^{t}, i^{t}\right) \cdot \tilde{q}_{c, 3}^{t}\left(i^{t}\right)-C V_{c, \bar{s}}^{t}\left(q_{c, 3}^{t}, \tilde{q}_{c, 3}^{t}, i^{t}\right) \cdot\left(q_{c, 3}^{t}+\tilde{q}_{c, 3}^{t}\right) \\
- \text { Pen. }\left(D_{3}^{t}\left(i^{t}\right)-\sum_{c} q_{c, 3}^{t}\right) \cdot\left(e_{c}^{t}\left(i^{t}\right)-q_{c, 3}^{t}\right)
\end{gathered}
$$

Subject to:

$$
\begin{array}{ll}
q_{c, 3}^{t}\left(i^{t}\right) \leq e_{c}^{t-1}\left(\hat{\imath}^{t}\right) & \left(\delta_{c}^{t}\right) \\
\tilde{q}_{c, 3}^{t}\left(i^{t}\right) \cdot\left(e_{c}^{t-1}\left(\hat{\imath}^{t}\right)-q_{c, 3}^{t}\right)=0 & \left(\varepsilon_{c}^{t}\right) \\
q_{c, 3}^{t}\left(i^{t}\right)+\tilde{q}_{c, 3}^{t}\left(i^{t}\right) \leq K_{c}^{t}\left(i^{t}\right) \cdot L_{3} & \left(\eta_{c}^{t}\right) \\
\sum_{c} q_{c, 3}^{t}\left(i^{t}\right)+\sum_{c} \tilde{q}_{c, 3}^{t}\left(i^{t}\right) \leq D_{3}^{t}\left(i^{t}\right) & \left(\lambda_{c}^{t}\right) \\
q_{c, 3}^{t}, \tilde{q}_{c, 3}^{t}, \delta_{c}^{t}, \eta_{c}^{t}, \lambda_{c}^{t} \geq 0 ; \quad \varepsilon_{c}^{t} \quad \text { free } &
\end{array}
$$

Where,

$$
\begin{array}{ll}
\hat{\imath}^{t} & \text { Direct predecessor of } i^{t} \\
S^{t-1}\left(\hat{\imath}^{t}\right) \leq P_{3}^{t}\left(i^{t}\right) & \text { Strike price predetermined in the last period (auction of the mechanism) } \\
& \text { supposed to be lower than peak season electricity price (€/MWh) } \\
q_{c, 3}^{t} & \text { Quantity produced by c that comes from their commitment (MWh) } \\
\tilde{q}_{c, 3}^{t} & \text { Additional production of c after fulfilling their commitment (MWh) } \\
\text { Pen. }\left(D_{3}^{t}\left(i^{t}\right)-\sum_{c} q_{c, 3}^{t}\right) & \text { The penalty paid by c per MWh of production below their committed } \\
& \text { quantity (€/MWh) } \\
P e n & \text { A constant of the penalty function } \\
\delta_{c}^{t}, \eta_{c}^{t}, \lambda_{c}^{t}, \varepsilon_{c}^{t} & \text { Dual variables of the constraints }
\end{array}
$$

The first term in (10) represents the generator's income earned from sales in the market. The electricity price is capped by the strike price $S^{t-1}($.$) for the quantity q_{c, 3}^{t}$ that comes for the commitment made at the auction mechanism. After fulfilling their commitment $\left(e_{c}^{t}\left(i^{t}\right)=q_{c, 3}^{t}\right)$, a generator can offer an additional quantity $\tilde{q}_{c, 3}^{t}$ in the market and receives the electricity price $P_{3}^{t}($.$) . The third terms represents the total variable cost of all$ quantities produced. The fourth term shows the penalty to be paid by the generator $\mathrm{c}$ whenever their commitments are not satisfied, $q_{c, 3}^{t}()<.e_{c}^{t}($.$) . The penalty is supposed to be$ endogenous to the reliability in the system, represented by $\left(D_{3}^{t}\left(i^{t}\right)-\sum_{c} q_{c, 3}^{t}\right)$.

Constraints (11) and (12) show that generators have first to fulfill their commitments in order to offer additional quantities and to receive the electricity price. Constraints (13) and 
(14) prevent the firm's production from exceeding its installed capacity and the total quantity produced from exceeding the demand level.

Operating decisions at this stage are made on the basis of the last period commitment decisions. So when this sub-model is solved, the optimal operating decisions $q_{c, 3}^{t *}$ and $\tilde{q}_{c, 3}^{t *}$, are functions of $e_{c}^{t-1}($.$) .$

Based on mixed complementarity problem method and regrouping together all first order optimality conditions for all generators, optimal operating decisions at the peak season are found as follows (see Appendix 1 for more details and proof):

- If $\sum_{c} e_{c}^{t-1}\left(\hat{\imath}^{t}\right)=D_{3}^{t}\left(i^{t}\right)$, then $q_{c, 3}^{t *}=e_{c}^{t-1}\left(\hat{\imath}^{t}\right)$ and $\tilde{q}_{c, 3}^{t *}=0$. Each generator produces their committed quantity whenever the total quantity sold by all generators at the auction of the mechanism corresponds to the demand level of the peak season.

- If $\sum_{c} e_{c}^{t-1}\left(\hat{\imath}^{t}\right)>D_{3}^{t}\left(i^{t}\right)$, then $q_{c, 3}^{t *}=f_{1, c} \cdot e_{c}^{t-1}\left(\hat{\imath}^{t}\right)+f_{2, c} \cdot e_{c^{\prime}}^{t-1}\left(\hat{\imath}^{t}\right)+f_{3, c}$ and $\widetilde{q}_{c, 3}^{t *}=0$. Where, $f_{1, c}, f_{2, c}, f_{3, c}$ are constants depending on the strike price, the penalty, constants of the variable cost function of $\mathrm{c}$ and the total quantity sold in the auction of the mechanism.

Generator c's production is a linear function of their committed quantity and the commitment of other generators whenever the total committed quantity exceeds the demand level of the season.

- If $\sum_{c} e_{c}^{t-1}\left(\hat{\imath}^{t}\right)<D_{3}^{t}\left(i^{t}\right)$, then $q_{c, 3}^{t *}=e_{c}^{t-1}\left(\hat{\imath}^{t}\right)$ and $\tilde{q}_{c, 3}^{t *}=f\left(D_{3}^{t}\left(i^{t}\right), K_{c}^{t}\left(i^{t}\right), e_{c}^{t-1}\left(\hat{l}^{t}\right), e_{c}^{t-1}\left(\hat{\imath}^{t}\right)\right)$. The generator satisfies first their commitment and could produce additional quantity depending on their installed capacity and the demand level whenever the total committed quantity is below the demand in the peak stage.

The reaction functions $q_{c, 3}^{t *}\left(e_{c}^{t-1}\right)$ and $\tilde{q}_{c, 3}^{t *}\left(e_{c}^{t-1}\right)$ are introduced now in the submodel of the mechanism stage in order to find optimal commitment decisions.

\subsubsection{Mechanism stage}

As explained in Section 2.2, the system operator purchases ex ante commitments from generators to produce in the future period a prescribed quantity of energy (highest expected peak demand). The method is based on the financial call option principle with auction procedure. We get the following assumptions for the realization of the auction:

- The auction is supposed to be organized one year ahead of real time.

- The time horizon: the peak season of the future period; the generators are required to offer their committed quantity at any time during that period.

- The quantity purchased by the system operator on behalf of all demand equals the highest expected peak. 
- The system operator sets the strike price $^{11}$ exogenously; the strike price level corresponds to the variable cost of an efficient marginal generator unit.

- Each generator submits one bid to the auction, expressing the quantity they want to sell and price (the required premium).

- The market is cleared as a simple auction and all of the accepted bids receive the premium that was solicited by the marginal bid.

Knowing these auction parameters, each generator maximizes the sum of his revenue from the auction and expected profit in the future peak season. The associated generator's sub-model is defined as follows:

$$
\max _{e_{c}^{t}} \operatorname{Pr}_{o p t}^{t}\left(i^{t}\right) \cdot e_{c}^{t}\left(i^{t}\right)+E_{w^{D}}\left[g_{c, 3}^{t+1 *}\left(q_{c, 3}^{t+1 *}\left(e_{c}^{t}\right), \tilde{q}_{c, 3}^{t+1 *}\left(e_{c}^{t}\right), \bar{Q}^{t}, \tilde{i}^{t}\right)\right]
$$

Subject to:

$$
\begin{aligned}
& e_{c}^{t}\left(i^{t}\right) \leq K_{c}^{t+1}\left(\tilde{l}^{t}\right) \cdot L_{3} \\
& e_{c}^{t}\left(i^{t}\right) \leq\left\{\bar{Q}^{t}\left(i^{t}\right), \bar{Q}^{t}\left(i^{t}\right)-e_{c^{\prime}}^{t}\left(i^{t}\right), \bar{Q}^{t}\left(i^{t}\right)-\sum_{c^{\prime}} e_{c^{\prime}}^{t}\left(i^{t}\right)\right\} \\
& \sum_{c} e_{c}^{t}\left(i^{t}\right) \leq \bar{Q}^{t}\left(i^{t}\right) \\
& e_{c}^{t}, \dot{\alpha}_{c}^{t}, \dot{\varepsilon}_{c}^{t}, \dot{\eta}_{c}^{t} \geq 0
\end{aligned}
$$

Where,

$g_{c, 3}^{t+1 *}($.$) \quad Expected optimal pay-off in the future peak period depending on commitment decision$ of $\mathrm{c}(€)$

$\bar{Q}^{t}\left(i^{t}\right) \quad$ Quantity purchased by the SO. It corresponds to the expected highest peak demand (MWh)

$\operatorname{Pr}_{\text {opt }}^{t}\left(i^{t}\right) \quad$ The auction price corresponding to the premium solicited by the marginal bid (€/MWh)

$e_{c}^{t}, \dot{\alpha}_{c}^{t}, \dot{\varepsilon}_{c}^{t}, \dot{\eta}_{c}^{t} \quad$ Dual variables of the constraints

In a Nash-Cournot manner, the generators decide simultaneously the quantity $e_{c}^{t}($.$) to$ be sold in the auction. They take into account their pay-offs in the future peak season $g_{c, 3}^{t+1 *}($. since it depends on their actual commitment decisions. Constraints (16) and (18) prevent respectively the firm's commitment from exceeding its expected installed capacity and the total committed quantity from exceeding the quantity requested by the SO. Constraint (17) shows that generator c can offer up to $\bar{Q}^{t}\left(i^{t}\right)$ if they have the lowest bid price, until $\bar{Q}^{t}\left(i^{t}\right)-$ $e_{c^{\prime}}^{t}\left(i^{t}\right)$ if only the bid price of generator c' is lower than their offer and finally until $\bar{Q}^{t}\left(i^{t}\right)-$ $\sum_{c^{\prime}} e_{c^{\prime}}^{t}\left(i^{t}\right)$ if their offer is the highest among the offers retained in the market.

We suppose that each generator offers a 'marginal' premium which guarantees minimum revenue for rational players. This is a reasonable assumption when players are single generating units acting alone in competition with other generators.

\footnotetext{
${ }^{11}$ It acts as a price cap for demand.
} 
When participating in the auction, the generator knows that their revenue in the future peak season will be capped by the strike price. So their required premium would rationally incorporate the income that they will not receive from the spot market. It corresponds to the difference between the expected electricity price, calculated apart by assuming that the generator does not participate in the auction, and the strike price. If, however, the generator is a non-competitive one and the electricity price cannot, of itself, cover both their operating and investment cost, they would formulate a premium that covers the difference between the total expected cost and the strike price. Therefore the premium requested by generator $\mathrm{c}$ is:

$\operatorname{Pr}_{c}^{t}\left(i^{t}\right)=\max \left\{E_{w^{D}}\left(P_{3}^{t+1}\left(\bar{q}_{c, 3}^{t+1}, \tilde{l}^{t}\right)\right)-S^{t}\left(i^{t}\right) ; E_{w^{D}}\left(U C_{3}^{t+1}\left(\bar{q}_{c, 3}^{t+1}, \tilde{l}^{t}\right)\right)-S^{t}\left(i^{t}\right)\right\}$

Where,

$\operatorname{Pr}_{c}^{t}\left(i^{t}\right) \quad$ The premium offered by the generator c (€/MWh)

$P_{3}^{t+1}\left(\tilde{l}^{t}\right) \quad$ Electricity price in the future peak season, if generator c does not participate in the auction ( $€ / \mathrm{MWh})$

$U C_{3}^{t+1}\left(\tilde{\imath}^{t}\right) \quad$ Unitary total cost of generator c's at future peak season (€/MWh)

$\bar{q}_{c, 3}^{t+1}\left(\tilde{l}^{t}\right) \quad$ Operating decision of generator $\mathrm{c}$ at the future peak season if they do not participate in the auction (MWh)

Rationally, each generator is induced to offer all their installed capacity in the auction. In fact, the premium earned from the auction will be at least equal to their required premium and participating in the mechanism will at least assure the same profit as non-participation. In this last case, they should take into account the fact that their competitors will offer their installed capacity in the auction and therefore their expected operating decision is found by:

$$
\bar{q}_{c, 3}^{t+1}=\operatorname{argmax}\left(P_{3}^{t+1}\left(\bar{q}_{c, 3}^{t+1}, K_{c}^{t+1}, \tilde{l}^{t}\right)-C V_{c, 3}^{t+1}\left(q_{c, \bar{s}^{\prime}}^{t} \tilde{l}^{t}\right)\right) \cdot \bar{q}_{c, 3}^{t+1}\left(\tilde{l}^{t}\right)
$$

Subject to

$$
\begin{aligned}
& \bar{q}_{c, 3}^{t+1} \leq K_{c}^{t+1}\left(\tilde{i}^{t}\right) \cdot L_{3} \\
& \bar{q}_{c, 3}^{t+1} \leq D_{3}^{t}\left(i^{t}\right)-\sum_{c^{\prime}} K_{c^{\prime}}^{t+1}
\end{aligned}
$$

After calculating the premium function specific to each generator, we can deduce the price of the auction $\operatorname{Pr}_{o p t}^{t}($.$) :$

$\operatorname{Pr}_{\text {opt }}^{t}\left(i^{t}\right)=\operatorname{Pr}_{c}^{t}\left(i^{t}\right)$ if $\operatorname{Pr}_{c}^{t}\left(i^{t}\right)$ is the highest and $e_{c}^{t}\left(i^{t}\right)>0$

Finally, it is important to note that the expected pay-off in the future peak season $g_{c, 3}^{t+1 *}($.$) in (15) depends on the level of \sum_{c} e_{c}^{t}()-.D_{3}^{t+1}($.$) , as shown in Section 3.1.2.a.$ Owing, however, to the incentive given by the auction for generators to offer the highest quantity, we assume that:

$$
\begin{aligned}
& \text { - } \quad \sum_{c} e_{c}^{t}(.)=\bar{Q}^{t}\left(i^{t}\right) \quad \text { if } \bar{Q}^{t}\left(i^{t}\right)<\sum_{c} K_{c}^{t+1} \\
& \text { - } \quad \sum_{c} e_{c}^{t}(.)=\sum_{c} K_{c}^{t+1} \quad \text { if } \bar{Q}^{t}\left(i^{t}\right) \geq \sum_{c} K_{c}^{t+1}
\end{aligned}
$$


Therefore, $g_{c, 3}^{t+1 *}($.$) is a continuous function that depends only on parameters \bar{Q}^{t}($. and $K_{c}^{t+1}($.$) and so the objective function (15) is a monotone function and the respective sub-$ model can be handled by the mixed complementarity problem method.

After the sub-model is solved, optimal commitment decisions and future peak season operating decisions are found function of the level of generator's installed capacity: $e_{c}^{t *}\left(K_{c}^{t+1}, K_{c^{\prime}}^{t+1}\right), q_{c, 3}^{t *}\left(K_{c}^{t+1}, K_{c^{\prime}}^{t+1}\right)$ and $\tilde{q}_{c, 3}^{t *}\left(K_{c}^{t+1}, K_{c^{\prime}}^{t+1}\right)$.

\section{$\underline{3.1 .4 \text { Investment stage }}$}

After determining optimal operating and commitment decision functions of generators' installed capacity levels, we formulate a stochastic dynamic sub-model, which takes the form of Bellman's equation, as described in Bertsekas (1959), in order to find generators' investment decisions. These decisions are discrete ones. A sequential NashCournot equilibrium is calculated by supposing that there is a leader firm (L) which decides first, a second firm (F1) which operates as a follower of L and a third firm (F2) operating as a second follower of $\mathrm{L}$ and F1 (see Section 2.2). The decision rule gives the yearly decisions depending on the information available when the decisions have to be made, such as demand level, generators' installed capacities and past information about investment decisions.

The mathematical formulation of the investment problem is described as follows:

$$
\begin{gathered}
J_{c}^{t}\left(i^{t}\right)= \\
\max _{u_{c}^{t}} \sum_{s} g_{c, s}^{t}\left(q_{c, s^{\prime}}^{t *} \tilde{q}_{c, 3}^{t *}, q_{c^{\prime}, s^{\prime}}^{t *} \tilde{q}_{c^{\prime}, 3^{\prime}}^{t *}, K_{c}^{t}, K_{c^{\prime}}^{t}, u_{c^{\prime}}^{t}, i^{t}\right)+z_{c}^{t}\left(e_{c}^{t *}, K_{c^{\prime}}^{t}, K_{c^{\prime}}^{t}, i^{t}\right)-i c_{c^{\prime}}^{t} \cdot K_{c}^{t}\left(i^{t}\right)+ \\
(1+r)^{-1} \cdot E_{w^{D, t}}\left(J_{c}^{t+1}\left(f\left(K_{c}^{t}, K_{c^{\prime}}^{t} u_{c}^{t}, u_{c^{\prime}}^{t}\right)\right)\right)
\end{gathered}
$$

Subject to

$K_{c}^{t+l t_{c}}\left(\bar{l}^{t}\right)=K_{c}^{t}\left(i^{t}\right)+u_{c}^{t}\left(i^{t}\right)$

Where,

$J_{c}^{t} \quad$ Max expected pay-off in period $\mathrm{t}(€)$

$J_{c}^{t+1} \quad$ Optimal expected pay-off in period $t+1$, corresponding to period t's optimal investment decisions $(€)$

$f($.$) \quad Future profits from period t to final period that correspond to generator's investment$ decisions made at period $\mathrm{t}$

Based on backward induction, the resolution starts from the end and goes back to the beginning of the planning period. At each period, generator $\mathrm{c}$ maximizes their expected total profit which corresponds to the sum of their profit in the current period - market revenue plus mechanism revenue - and their optimal expected profit in future periods minus investment costs. We suppose that each generator pays a constant annuity $i c_{c}^{t}$ calculated from the total investment cost that would be paid over the lifetime of the plant. 
Owing to the presence of construction delays that differ according to the generator's specialization, we suppose that if an expansion decision is made, additional investments cannot be made until the ongoing construction period is finalized.

\subsection{Forward Capacity Market models (Models B1 and B2)}

Two variants of capacity market mechanism are modeled here. The first one (Model B1) has the same assumptions as the reliability options model. The overall game is also described as a repeated three-stage dynamic game where competition takes place in three steps: investment, commitment and operating decisions. In the mechanism stage, a capacity market is organized via an auction procedure where generators sell capacity (and not quantity) and they are committed to making it available whenever they are called to do so in the future period (peak season).

For the second model (Model B2), we use a specific function that reflects the market's demand for capacity and expresses the relationship between the generator's payment from capacity market and the expected reliability in the system. We suppose that capacity price is determined by the capacity demand function, instead of the auction procedure.

\subsection{1: Model B1: auction procedure}

We use the same description and assumptions employed in Model A. The differences, however, concern the sub-models of the mechanism stage and the peak season.

In the mechanism stage, as explained in Section 2.2, the system operator purchases ex ante, via an auction procedure, commitments from generators to have available in the future period a prescribed capacity level (highest expected peak demand). We get the following assumptions for the realization of the auction:

- The auction is organized one year ahead of real time.

- The time horizon: the peak season of the future period; the generators are required to offer their committed capacity at any time during that period.

- The capacity purchased by the system operator on behalf of all demand corresponds to the highest expected peak demand.

- No strike price is explicitly defined but in the peak season of the future period, generators are required to refund to consumers any infra-marginal rents for their contracted capacity. We can therefore define it as an implicit strike price.

- Each generator submits one bid to the auction, expressing the capacity they want to sell and the price (the required premium).

- The market is cleared as a simple auction and all of the accepted bids receive the premium that was solicited by the marginal bid.

Compared with the sub-model used in Section 3.1.3, the unique difference concerns the required premium offered by generators. It is redefined as:

$\operatorname{Pr}_{c}^{t}\left(i^{t}\right)=\max \left\{E_{w^{D}}\left(P_{3}^{t+1}\left(\bar{q}_{c, 3}^{t+1}, \tilde{l}^{t}\right)-C m_{\bar{c}, \bar{s}}^{t}\left(i^{t}\right)\right) ; E_{w^{D}}\left(U C_{3}^{t+1}\left(\bar{q}_{c, 3}^{t+1}, \tilde{l}^{t}\right)-C m_{\bar{c}, \bar{s}}^{t}\left(i^{t}\right)\right)\right\}$ 
Where,

$\operatorname{Cm}_{\bar{c}, \bar{s}}^{t}\left(q_{\bar{c}, 3}^{t}, \tilde{q}_{\bar{c}, 3}^{t}, i^{t}\right) \quad$ Marginal cost of the peak generator (€/MWh)

In fact, when generators are called to offer their contracted capacity in the spot market, they are also required to refund the consumers any infra-marginal rent corresponding to the difference between the spot price and the marginal cost of peak generator $C m_{\bar{c}, \bar{s}}^{t}($.$) . While the$ strike price is exogenous and fixed ex ante in the reliability option model, it is endogenous and uncertain in this model.

Therefore, the generator's profit associated with the peak season can be redefined as:

$$
\begin{gathered}
g_{c, 3}^{t}=P_{3}^{t}\left(Q_{3}^{t}, D_{3}^{t}, i^{t}\right) \cdot\left(q_{c, 3}^{t}+\tilde{q}_{c, 3}^{t}\right)-\left(P_{3}^{t}\left(Q_{3}^{t}, D_{3}^{t}, i^{t}\right)-C m_{\bar{c}, \bar{s}}^{t}\left(q_{\bar{c}, 3}^{t}, \tilde{q}_{\bar{c}, 3}^{t}, i^{t}\right)\right) \cdot q_{c, 3}^{t} \\
-C V_{c, \bar{s}}^{t}\left(q_{c, 3}^{t}, \tilde{q}_{c, 3}^{t}, i^{t}\right) \cdot\left(q_{c, 3}^{t}+\tilde{q}_{c, 3}^{t}\right)-P e n \cdot\left(D_{3}^{t}\left(i^{t}\right)-\sum_{c} q_{c, 3}^{t}\right) \cdot\left(e_{c}^{t}\left(i^{t}\right)-q_{c, 3}^{t}\right)
\end{gathered}
$$

As in model A, generators decide in the peak season the quantity to be produced that come from their commitments $q_{c, 3}^{t}($.$) . If they fulfil their commitments, they can offer$ additional quantities $\widetilde{q}_{c, 3}^{t}($.$) . The generator earns the spot price P_{3}^{t}($.$) for the total quantity$ produced, but is required to refund consumers the infra-marginal rents for all their contracted quantity (second term in (26)). Finally, the generator pays a penalty fee whenever their commitments are not satisfied.

\subsection{2: Model B2: capacity demand function}

Compared with model B1, the auction in the mechanism stage is replaced by a specific capacity demand function ${ }^{12}$, equation (27).

$\operatorname{Pcap}_{c}^{t}\left(i^{t}\right)=h+n \cdot\left(\bar{Q}^{t}\left(i^{t}\right)-\sum_{c} e_{c}^{t}\left(i^{t}\right)\right)$

Where,

$\operatorname{Pcap}_{c}^{t}\left(i^{t}\right) \quad$ Capacity price (€/MWh)

$\mathrm{h}$ and $\mathrm{n} \quad$ Constants of the capacity demand function

The function expresses the relationship between the generator's payment from the capacity market and the difference between the quantity required by the SO and the contracted capacity. This function reflects the market's demand for capacity, where the payment increases as the reliability decreases.

The generators' sub-model in the mechanism stage is now reformulated as:

$$
\max _{e_{c}^{t}} \operatorname{Pcap}_{c}^{t}\left(i^{t}\right) \cdot e_{c}^{t}\left(i^{t}\right)+E_{w^{D}}\left[g_{c, 3}^{t+1 *}\left(q_{c, 3}^{t+1 *}\left(e_{c}^{t}\right), \tilde{q}_{c, 3}^{t+1 *}\left(e_{c}^{t}\right), \bar{Q}^{t}, \tilde{i}^{t}\right)\right]
$$

\footnotetext{
${ }^{12}$ It is an approximation of the traditional capacity market implemented in the USA.
} 
Subject to:

$e_{c}^{t}\left(i^{t}\right) \leq K_{c}^{t+1}\left(\tilde{l}^{t}\right) \cdot L_{3}$

$\sum_{c} e_{c}^{t}\left(i^{t}\right) \leq \bar{Q}^{t}\left(i^{t}\right)$

Owing to the fact that the future peak season profit $g_{c, 3}^{t+1 *}($.$) in (28) depends on the$ level of $\sum_{c} e_{c}^{t}()-.D_{3}^{t+1}($.$) and that P \operatorname{cap} p_{c}^{t}(.) . e_{c}^{t}($.$) is not a strictly continuous function, the$ objective function in (28) cannot be handled by the MCP method. The solution is therefore found by an iterative procedure.

Finally, we note that optimal operating decisions and investment decisions are calculated by use of the same formulation applied in Models A and B1.

\subsection{Capacity payment model (Model C)}

Generators are given in peak seasons a fixed capacity payment for their installed capacity whether they produce or not. The game is represented by a two-stage dynamic model. Generators compete in a Nash-Cournot manner to find investment and operating decisions (no mechanism stage). The solution at each stage is found by application of the same method used for modelling the market-based incentive mechanisms.

The unique difference concerns the peak season sub-model. It is reformulated as follows:

$$
\begin{gathered}
\max _{q_{c, 3}^{t}} g_{c, 3}^{t}= \\
P_{3}^{t}\left(Q_{3}^{t}, D_{3}^{t}, i^{t}\right) \cdot q_{c, 3}^{t}\left(i^{t}\right)+P C \cdot K_{c}^{t}\left(i^{t}\right)-C V_{c, \bar{s}}^{t}\left(q_{c, 3}^{t}, i^{t}\right) \cdot q_{c, 3}^{t}
\end{gathered}
$$

Subject to:

$q_{c, 3}^{t}\left(i^{t}\right) \leq K_{c}^{t}\left(i^{t}\right) \cdot L_{3}$

$\sum_{c} q_{c, 3}^{t}\left(i^{t}\right) \leq D_{3}^{t}\left(i^{t}\right)$

Where,

$P C$

A constant capacity price (€/MW)

\subsection{Energy-Only Market model (Model D)}

Similarly to the capacity payment mechanism, only investment and operating decisions are made by generators. Furthermore, generators' revenues only result from their sales in the spot market. Therefore generators' sub-model for each season $\mathrm{s}$ is defined as:

$$
\begin{gathered}
\max _{q_{c, s}^{t}} g_{c, s}^{t}= \\
P_{S}^{t}\left(Q_{S}^{t}, D_{s}^{t}, i^{t}\right) \cdot q_{c, s}^{t}\left(i^{t}\right)-C V_{c, s}^{t}\left(q_{c, s}^{t}, i^{t}\right) \cdot q_{c, s}^{t}
\end{gathered}
$$


Subject to:

$q_{c, S}^{t}\left(i^{t}\right) \leq K_{c}^{t}\left(i^{t}\right) \cdot L_{S}$

$\sum_{c} q_{c, s}^{t}\left(i^{t}\right) \leq D_{S}^{t}\left(i^{t}\right)$

Investment decisions are found similarly to the market-based mechanisms by application of the stochastic dynamic programming method.

\subsection{Comparison between investment incentive mechanisms}

The objective of this study is to find which among these market designs is the best/most efficient in terms of ensuring long-term system adequacy, cost efficiency and price manipulations limitation. Three criteria are used to evaluate the different market designs. The first one is the evolution of peak capacity margins within the planning period. The second is the evolution of average peak prices and total incentive costs paid by end-users for each incentive mechanism. The third one concerns market price manipulation.

We also investigate how optimal competitors' strategies could change according to the structure of competition (competitive oligopoly, collusion and monopole).

\section{Case Study}

\subsection{General input data}

The parameters in the models are estimated from historical data for the French electricity market, ${ }^{13}$ and found in (Etudes DIGEC (1997), Etude DGEMP (2003) and Powernext Bilan Statistique). We have referred to annual historical data for load and electricity price in Powernext from 2001 to 2006 to estimate the parameters in the spot price model. Table 1 shows the main parameters used in the models.

\footnotetext{
${ }^{13}$ The opening of the French electricity market was achieved with the creation of Powernext SA in 2001.
} 


\begin{tabular}{|c|c|c|}
\hline Parameter & $\begin{array}{l}\text { NAME IN THE } \\
\text { MODELS }\end{array}$ & VALUE \\
\hline Initial installed capacity & $K_{1}^{0}, K_{2}^{0}$ and $K_{3}^{0}$ & $\begin{array}{l}67000(\mathrm{MW}), 20000(\mathrm{MW}) \text { and } 10000 \\
(\mathrm{MW})\end{array}$ \\
\hline Construction delays & $l t_{1}, l t_{2}$ and $l t_{3}$ & 5 years, 3 years and 2 years \\
\hline New installed capacity & $u_{1}^{t}, u_{2}^{t}$ and $u_{3}^{t}$ & 2000 (MW), 1500 (MW) and 1000 (MW) \\
\hline Initial load level & $D_{1}^{0}, D_{2}^{0}$ and $D_{3}^{0}$ & 63333(MW),78500(MW) and $95000(\mathrm{MW})$ \\
\hline Discount factor & $\beta$ & $1 /(1,08)$ \\
\hline Load growth & $w^{D}$ & $1300(\mathrm{MW})$ or $650(\mathrm{MW})$ \\
\hline Yearly Investment cost & $i c_{1}^{t}, i c_{2}^{t}$ and $i c_{3}^{t}$ & $\begin{array}{l}115300(€ / M W), 58400(€ / M W) \text { and } 30000 \\
(€ / M W)\end{array}$ \\
\hline Number of hours in the season & $L_{1}, L_{2}$ and $L_{3}$ & 4260 hours, 3000 (hours) and 1500 (hours) \\
\hline Parameters of price function & $b_{1}, b_{2}$ and $b_{3}$ & $5 * 10 \mathrm{E}-9,5 * 10 \mathrm{E}-8$ and $10 * 10 \mathrm{E}-7$ \\
\hline Parameters of variable cost function & $\begin{array}{l}d_{1, \bar{s}}, d_{2, \bar{s}} \text { and } \\
d_{3, \bar{s}}\end{array}$ & $9(€ / \mathrm{MWh}), 40(€ / \mathrm{MWh})$ and $80(€ / \mathrm{MWh})$ \\
\hline Parameters of variable cost function & $\begin{array}{l}r_{1, \bar{s}} \\
r_{2, \bar{s}} \text { and } r_{3, \bar{s}}\end{array}$ & $\begin{array}{l}4,13 * 10 \mathrm{E}-8\left(€ / \mathrm{MWh}^{2}\right), 6,38 * 10 \mathrm{E}-8 \\
\left(€ / \mathrm{MWh}^{2}\right) \text { and } 3 * 10 \mathrm{E}-7\left(€ / \mathrm{MWh}^{2}\right)\end{array}$ \\
\hline $\begin{array}{l}\text { Parameters of capacity demand } \\
\text { function }\end{array}$ & $\mathrm{h}$ and $\mathrm{n}$ & $18000(€ / \mathrm{MW})$ and $7 * 10 \mathrm{E}-7\left(€ / \mathrm{MW}^{2}\right)$, \\
\hline
\end{tabular}

Table 1: Initial input parameters for the models

There are three generators which are specialized in one production technology (plateau, off-plateau and peak). The plateau generator retains $70 \%$ of the total initial installed capacities, the off-plateau generator retains $25 \%$ and the peak generator $5 \%$. This distribution reflects the situation in some energy markets where a predominant generator has a large part of the power generating units, such as the French electricity market. They are in competition at two or three stages: investment and production for all mechanisms and also at commitment stage for market-based mechanisms.

We firstly compare results between the different mechanisms when generators compete in an oligopoly. Then, we repeat the analysis by supposing that two generators collude and compete with the third one and we finish by studying the monopolistic situation.

\subsection{Results}

In this section, we identify optimal investments, generating and commitment decisions and study whether investment incentive mechanisms (i.e. reliability options, forward capacity 
markets and capacity payments) facilitate long-term system adequacy. The capacity adequacy level is calculated by use of the capacity balance in the peak period. Optimal capacity adequacy is assured when the capacity margin is up to $4000 \mathrm{MW}$ in the peak season and is at least positive. The best mechanism will be the one that both ensures the optimal adequacy level and efficient relative costs for end-users and reduces price manipulations. We also investigate the consequences for generators' optimal strategies when different competitive scenarios are considered such as cartels and monopolistic scenarios. We finally show the results of a sensitivity analysis of the main parameters.

A planning horizon of sixteen years is used for the case study and the five market designs analyzed here are shown in Table 2.

\begin{tabular}{|l|l|}
\hline Market designs & \\
\hline EOM & Energy-only market \\
\hline RO & Reliability options \\
\hline CM1 & Forward capacity market with auction \\
\hline CM2 & Forward capacity market with capacity demand function \\
\hline CP & Capacity payments \\
\hline
\end{tabular}

Table 2: Definition of market designs in the case study

Parameters in the different scenarios are estimated on the assumption that additional payments will be identical at efficient thresholds. Indeed, in a perfect competitive situation the premium earned by generators in the auction of the RO and CM1 scenarios would be close to the investment cost of a peaking unit which corresponds to the 'missing money' encountered in the EOM scenario. Therefore we have set the capacity price in the CP scenario at this level. Moreover, in the CM2 scenario, parameters of the capacity demand's function are settled such that the additional payment corresponds to the investment cost of a peaking unit since system reliability is assured.

Result 1: the introduction of investment incentive mechanisms leads to more capacity additions than the energy-only market design. Only reliability options and forward capacity markets with auction procedure, however, ensure optimal capacity adequacy.

We can see from Figure 2 that when investment incentive mechanisms are introduced, the average capacity addition is higher from T6 to the end of the planning period, compared with the EOM design. This result confirms the theoretical predictions, which assume that economic signals of incentive mechanisms tend to augment the volume of installed and available capacity and the reliability of the system is enhanced. It is shown in Figure 3, however, that from T10 to the end of the planning period the capacity margin is higher than required in $\mathrm{CP}$ scenario, yielding overcapacity periods, and is negative with CM1 scenario.

As we expected, since available capacities are twice compensated when the capacity payment mechanism is applied, generators have more incentive to invest in the system in 
order to profit from this higher revenue, and the capacity additions increase slightly, yielding overcapacity situations, especially because no commitment to produce is imposed. On the other hand, in CM2 scenario the remuneration given by the mechanism is endogenous to the security in the market (difference between expected peak demand and committed capacity); the higher the commitment (security is assured), the more the remuneration decreases, so generators choose to wait until the system is close to rationing before they invest.

In RO and CM1 scenarios, additional payments given by the mechanisms (auction price) correspond efficiently to the cost of the reliability which is equivalent to the investment cost of the peak unit. The commitment to produce, which reduces market power, incites generators to invest only capacities that serve to meet expected future peak demand and long term capacity adequacy is assured in efficient manner.

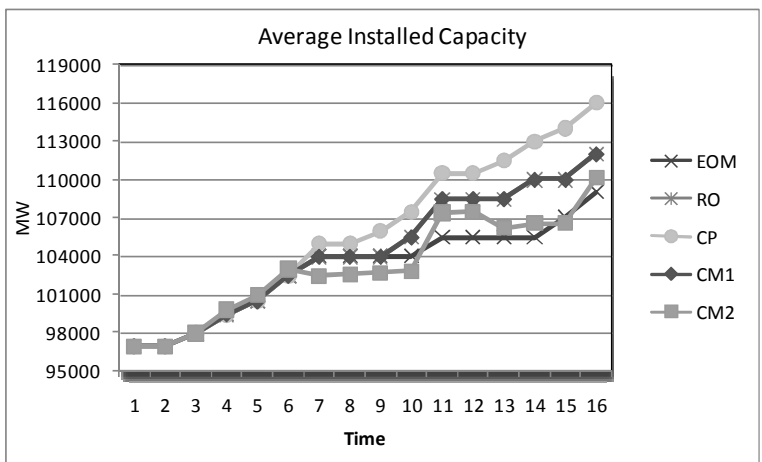

Figure 2. Average capacity expansion for the five market designs

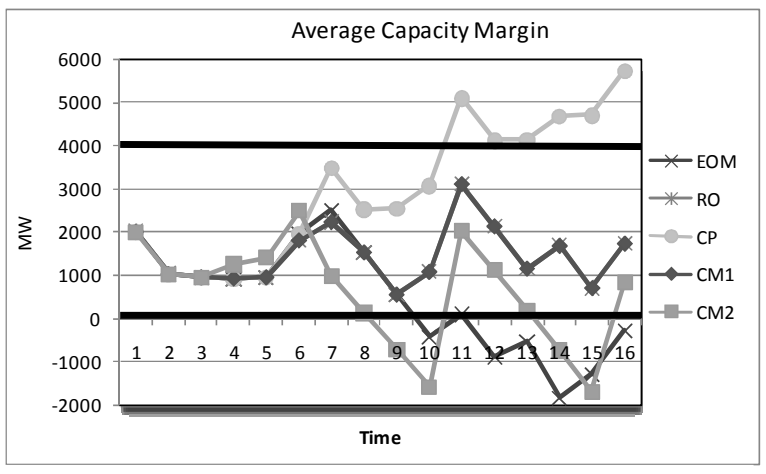

Figure 3. Average capacity balance for the five market designs

Owing to the presence of demand uncertainty in our models, we complete our results by calculating the standard deviation of the future capacity margin. Figure 4 shows that it evolves similarly in the different scenarios and does not exceed 1500 MW. This means that, in all scenarios, total existing capacity at each period is only slightly dependent on the demand state.

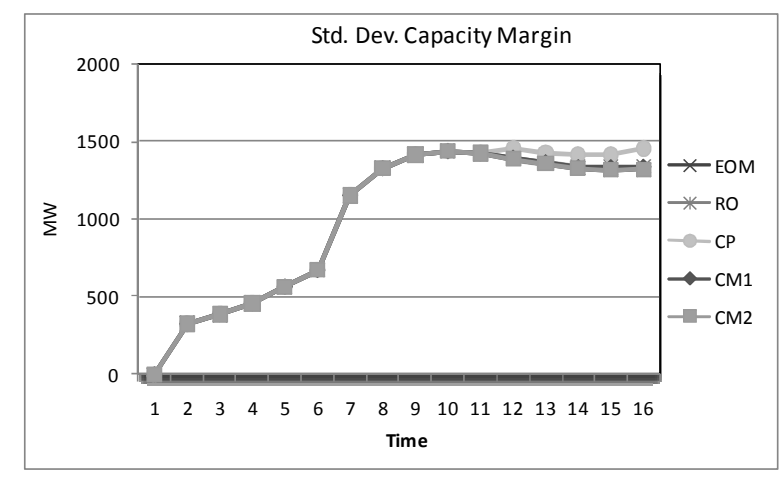

Figure 4. Standard deviation of capacity balance for the five market designs

Result 2: the market-based mechanisms provide lower peak spot prices.

With the market-based mechanisms (RO, CM1 and CM2 scenarios), average peak prices are the lowest (Figure 6). On the one hand, the exogenous strike price imposed by the 
system operator in the reliability options mechanism and, on the other hand, the obligation for generators to refund consumers any infra-marginal rents earned at the peak period with forward capacity markets mechanisms, act as a price cap by preventing peak prices from reaching high levels, and thus consumers are fully protected from high prices in the energy market. With these mechanisms, consumers receive a maximum-price hedge in exchange for all the capacity they are contracting. In CP scenario, however, prices are still high and close to the energy-only market ones. An important weak point of the capacity payment design is that consumers remain fully exposed to the potential high prices in the energy market, and they pay a capacity charge and receive nothing in return. Also, according to our assumptions about imperfect competition, the lack of obligation to produce gives incentive to generators to manipulate spot prices.

Figure 7 shows the standard deviation levels of the future peak prices. They do not exceed $2 € / M W h$ with market-based mechanisms.

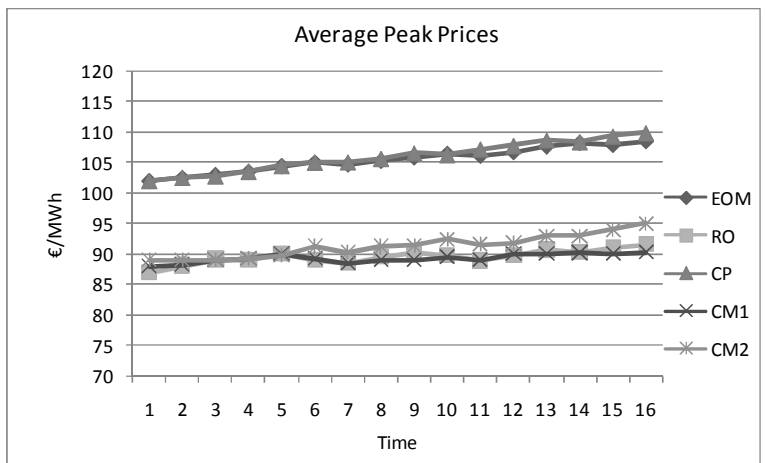

Figure 6. Average peak prices evolution for the fifth market designs

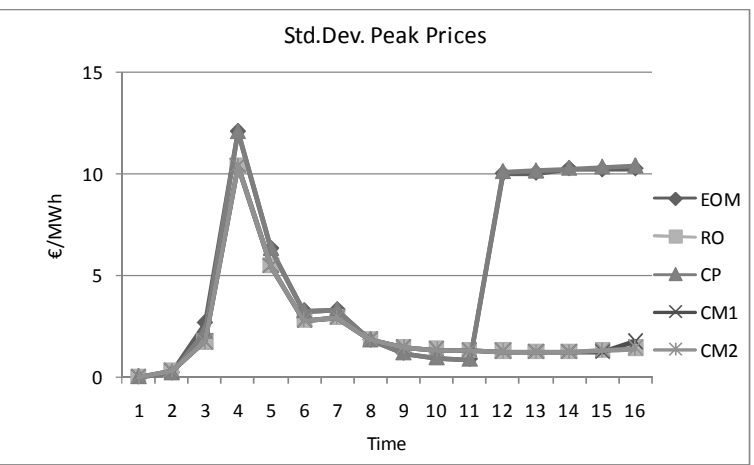

Figure 7. Standard deviation of peak prices for the fifth market designs

Result 3: reliability options and forward capacity markets with auction procedure are the most cost-efficient mechanisms and lead to a stabilization of consumers' payments.

Results 1 and 2 suggest that the EOM scenario would not give good signals for new capacity additions and would lead to high prices and insufficient capacity adequacy, especially at the end of the planning period, so the implementation of an additional incentive mechanism is needed.

The capacity payment mechanism, however, stimulates further capacity additions resulting in an over-capacity situation, yet with the highest peak prices of all scenarios.

In order to evaluate the market-based mechanisms better, we calculate the cost paid by consumers for all the capacity they contract. Figure 8 illustrates the evolution of this cost, which includes the peak price in the period and the specific incentive cost. It is stable and close to $105 € / \mathrm{MWh}$ over all periods in scenarios RC and CM1, while it is higher in $\mathrm{CP}$ scenario (up to almost 130€/MWh) and in CM2 scenario (up to 160€/MWh). 
Indeed, in this last scenario, specific incentive costs are largely dependent on the security level in the system, so generators manipulate the prices in the capacity market by offering less than the quantity requested by the system operator.

On the other hand, in $\mathrm{CP}$ scenario the specific incentive cost is exogenous and corresponds to the investment cost of the peaking unit. In theory, the total cost paid by consumers in a period should be close to those observed in RO and CM1 scenarios, that is, covering both the operating costs and the investment costs and resolving the missing money problem. Owing, however, to the fact that no obligation to produce is imposed on generators, they exert market power in the peak period, which leads to a shortages situation and high electricity prices in spite of the double remuneration of their installed capacities.

In RO and CM1 scenarios, the price of the contract (the premium) is set via a marketbased mechanism, with a limited amount of regulatory intervention, and provides a stable income for generators on the one hand and allows consumers to hedge against the occurrence of high prices and high additional incentive costs on the other. These mechanisms can be seen as market-compatible price caps where the problem of discouraging investments, induced by this price cap, is eliminated thanks to the incentive economic signal given by the stabilizing effects of the contract on the generators' revenues. Also, consumers obtain, in exchange for a stable payment, a satisfactory guarantee that there will be enough available generation capacity whenever it is needed.

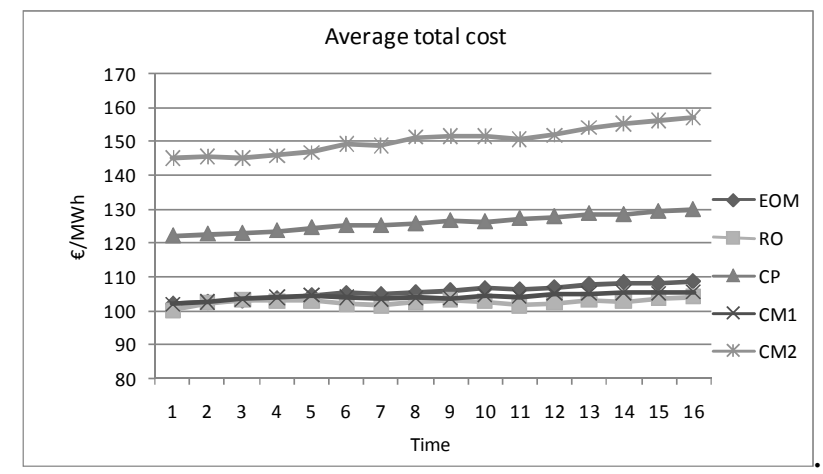

Figure 8. Average total cost evolution for the five market designs

\section{Result 4: in imperfect competition, generators exert market power when introducing non-market based mechanisms.}

We now study how generators can manipulate electricity prices and revenues. Figure 9 shows average energy balance in the peak period calculated by the difference between peak demand and generator's total production. First, in CP scenario, it is closely to $15 \mathrm{E}^{6} \mathrm{MWh}$ over the planning period, even though capacity balance is positive. We can suggest that, all other things being equal, a fixed capacity payment without commitment to produce cannot solve the problem of market power. Also, whatever the capacity balance level in EOM scenario, energy balance is positive and high and evolves closely with $\mathrm{CP}$ scenario.

Second, in CM2 scenario, energy balance is volatile and higher compared with RO and CM1 scenarios. This result is because of the lack of new capacity addition and the 
possibility of price manipulations even if capacity balance is positive. Consequently, the system will often be close to rationing.

Third, in RO and CM1 scenarios, average energy balances are the lowest and evolve closely to zero. The extra revenue is stable over the planning period and the penalty imposed on generators whenever their commitments are not satisfied in the peak period reduces the incentive to manipulate electricity prices, and thereafter, at all times, generators offer the quantities that correspond to the peak demand.

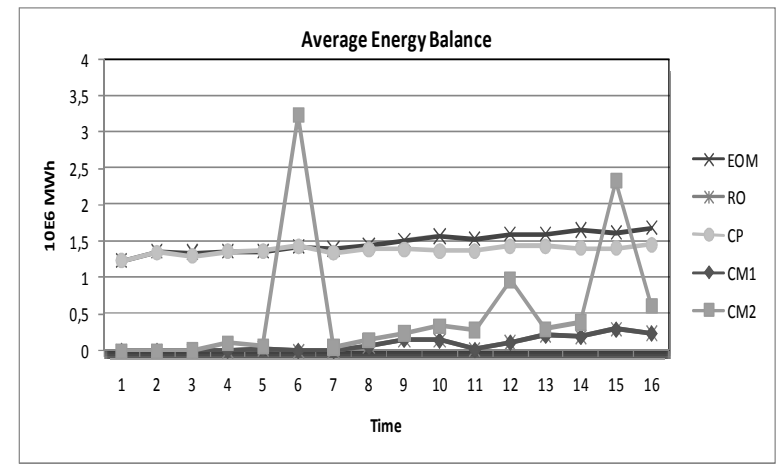

Figure 9. Average energy balance evolution for the five market designs

Result 5: Sensitivity Analysis: compared with Cournot competition, cartel and monopolistic situations lead to more installed capacities only with market-based mechanisms, increasing end-users payments for all scenarios.

We study now how results could change in cartel and monopolistic situations. Comparing outcomes in Figures 10 and 11 with those in Figure 3, note that in RO and CM1 scenarios, average capacity balance increases and reaches an overcapacity situation in monopolistic scenarios. Indeed, in these situations generators can manipulate premiums in the auction of the mechanism and, as a result, they increase their expected profit from the mechanism. Since this remuneration increases with the installed capacity, they are induced to invest more in the system until a non-socially acceptable range appears. In CM2 scenarios, however, average installed capacities decrease compared with the competitive scenario since the revenue from the capacity market is high in scarcity situations.

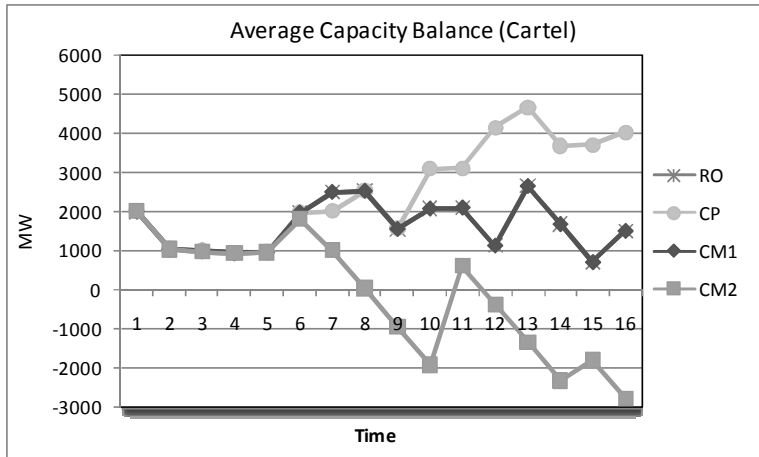

Figure 10. Average capacity balance evolution in cartel situation

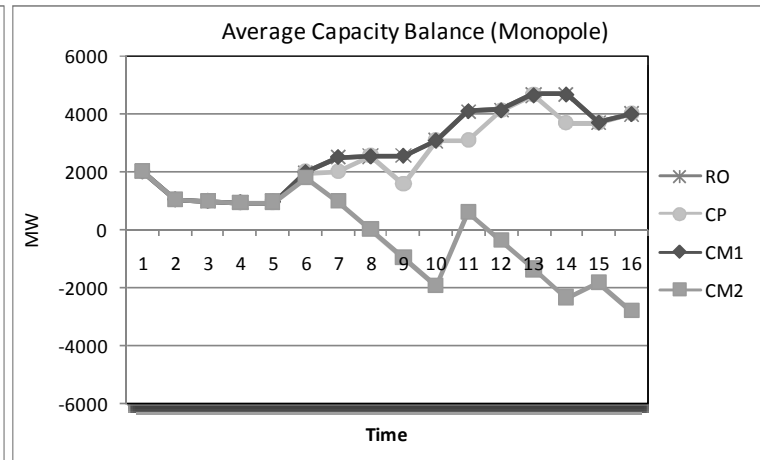

Figure 11. Average capacity balance evolution in monopolistic situation 
Moreover, as expected in theoretical predictions, aggregate profit increases as the number of non-colluding players in the industry decreases. This is proven in Figures 12 and 13 where, for all scenarios, average total cost is higher in cartel situations than in competitive situations and reaches a high level in monopolistic situations.

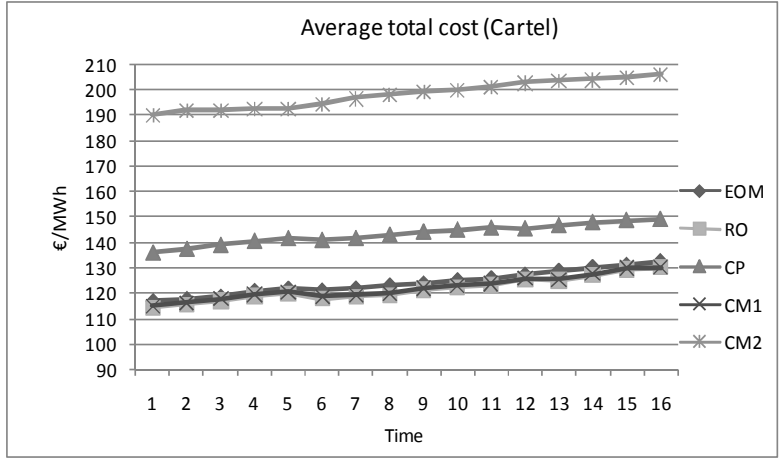

Figure 12. Average total cost evolution in cartel situation

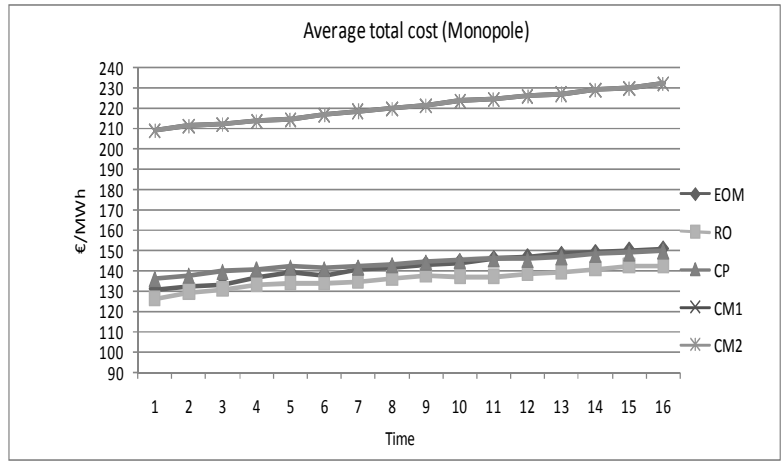

Figure 13. Average total cost evolution in monopolistic situation

Finally, results in Figures 14 and 15 show that in CP and CM2 scenarios generators exert more market power, which confirms analysis of the classical Cournot model, suggesting that total output would decrease in cartel and monopolistic situations. In RO and CM1 scenarios, however, generators cannot manipulate spot prices and thus average energy balances are close to levels observed in oligopolistic scenario.

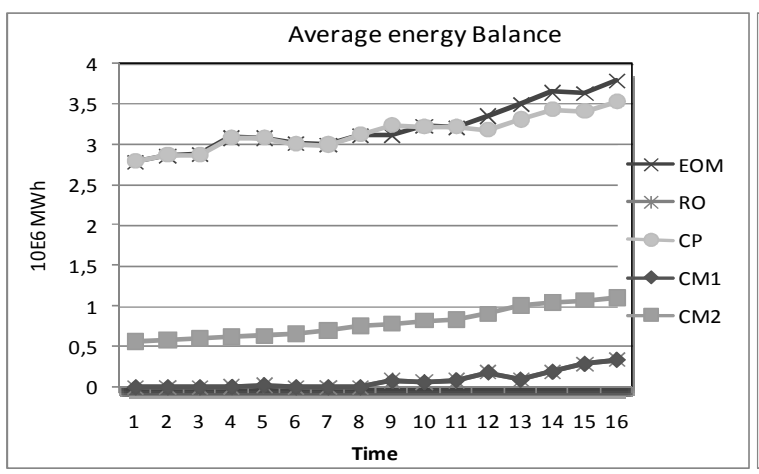

Figure 14. Average energy balance in cartel situation

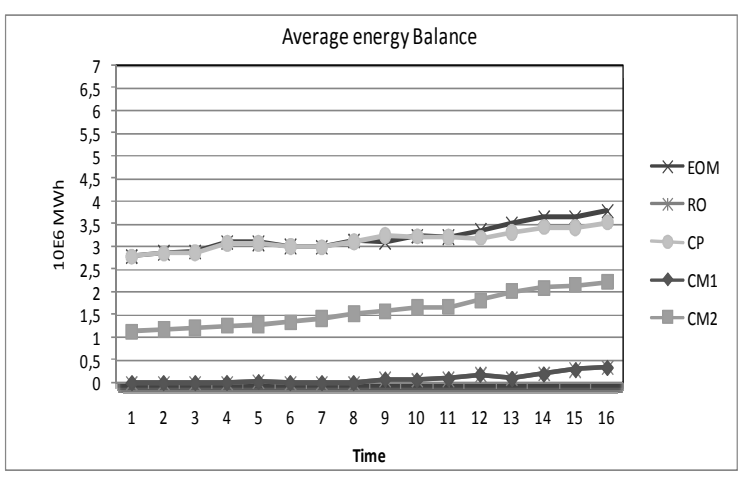

Figure 15. Average energy balance in monopolistic situation

Result 6: Sensitivity Analysis: the level of the exogenous strike price and the penalty charge would have no effect on optimal investors' strategies.

In order to study the sensitivity of our results to the main parameters, we repeated the analysis by varying the exogenous strike price in RO scenario. In practice, this would not have a major effect since generators would increase their required premium, which includes the difference between the expected spot price and the strike price fixed by the operator. Not surprisingly, we find no variations in investment decisions and total mechanism cost. Indeed, premiums required by generators increase when the strike price is diminished and decrease when it rises; the total mechanism cost, however, does not change. 
Similarly, the level of the penalty has no impact on our results since it is at least equal to variable cost of the peaking unit.

\section{Result 7: in cartel and monopolistic situations, auction prices in reliability options and forward capacity markets scenarios are manipulated}

Finally, we study the behaviors of generators when they participate in the auction of the market-based mechanisms. Figures 16 and 17 show the evolution of auction price and consumer's surplus respectively in RO scenarios. Auction price is the lowest in the competitive scenario and corresponds to the part that covers both operating and investment cost of the peaking unit.

In cartel and monopolistic situations, however, the auction price increases. Indeed, generators can now manipulate more the expected peak price that serves to calculate their premiums, by reducing the production level needed to calculate that price (see Section 3.1.3).

Moreover, consumers' surplus, which corresponds to the difference between peak price calculated without commitments and total mechanism cost, is positive and increasing in competitive scenario, though it is low and decreasing in cartel and monopoly situations, which confirms that auction prices are manipulated when generators collude. We also note that in CM1 scenario, generators behave similarly to RO scenario. Indeed, the difference between the two mechanisms concerns only the strike price but the premiums requested by generators in the auction of the mechanisms are equivalent.

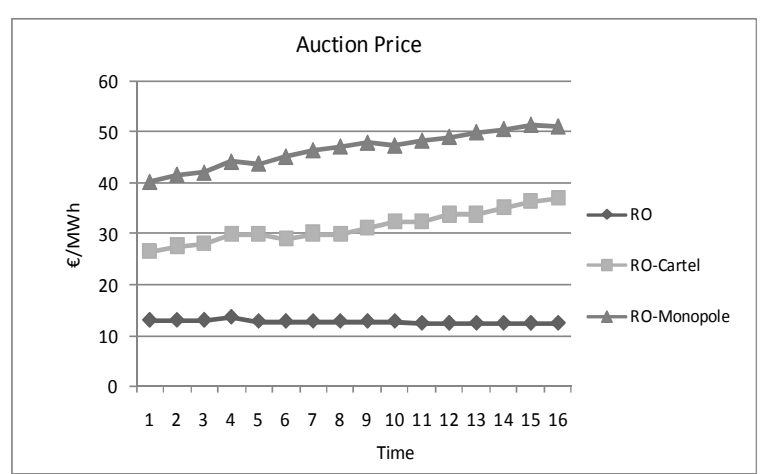

Figure 16. Auction prices in reliability options scenario

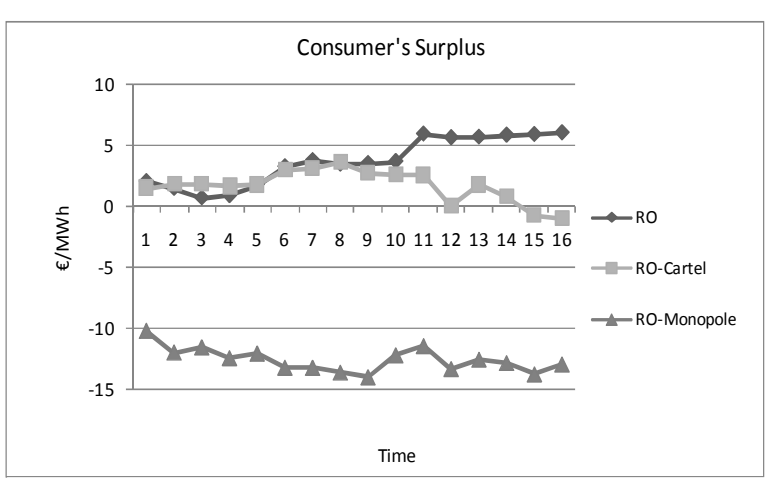

Figure 17. Consumers' surplus evolution in reliability options scenario

\section{Conclusion}

In this paper, we have illustrated, based on the dynamic programming method and mixed complementarity problem formulation, five stochastic dynamic models for addressing the problem of long-term capacity adequacy in electricity markets. Three investment incentive mechanisms, reliability options, forward capacity markets and capacity payments are analyzed and compared with the benchmark design, the energy-only market, in order to find the optimal market design to ensure adequate new investments in the system and sufficient generation capacity to meet future demand at efficient cost and reduce market power. We 
apply the Nash-Cournot model of oligopoly behaviour to formulate a three-stage model that characterizes three decisions in an imperfect competitive regime: expansion planning, generation decisions and commitment decisions (commitment to produce when market-based mechanisms are applied). We also compare the results of oligopoly behaviour with those obtained in monopolistic situations to see if some generators collude. A closed-loop solution of the overall game is found for each scenario.

The main finding of this study is that market-based mechanisms would be the more cost-efficient mechanisms for ensuring long-term system adequacy and encouraging earlier and adequate new investments in the system. Moreover, generators would exert market power when introducing the non-market based mechanisms. Finally, compared with Cournot competition, cartel and monopolistic situations lead to more installed capacities with marketbased mechanisms and increase end-users' payments.

This analysis could be extended in several ways. First, we could study the effect of other mechanisms such as capacity subscriptions. Second, the feedback of the demand side to the implementation of an incentive mechanism could also be analysed.

\section{REFERENCES}

Bertsekas D.P. (2000). "Dynamic Programming and Optimal Control”, 2nd edition, Athena Scientific.

Bilan Statistique 2002-2003-2004-2005, Powernext Day-AheadTM, Pwernext FuturesTM.

Botterud, A. (2003). "Long-term planning in restructured power system: Dynamic modelling of investments in new power generation under uncertainty", Ph.D. Thesis, Department of Electric Power Engineering, Norwegian University of Science and Technology, Trondheim, Norway.

Botterud, A., Ilic, M. and Wangensteen, I. (2005). "Optimal Investment in power Generation Under Centralised and Decentralised Decision Making”, IEEE Transaction on Power System, vol 20, no 1 .

De Vries, L.J. (2004). "Securing the public interest in electricity generation markets: the myths of the invisible hand and the copper plate, $\mathrm{PhD}$ thesis, Technical University Delft, Delft, Netherlands.

Doorman, L (2003). "Capacity subscription and security of supply in deregulated electricity markets", SINTEF Energy Research N-7465 Trondheim, Norway.

Etudes DIGEC (1997) et EDF (1999), "Pour de nouvelles installations, les analyses traditionnelles concluent à la convergence des coûts des différentes filières mais avec des biais méthodologiques ». 
Etude «Coûts de référence de la production électrique » de la DGEMP, December 2003.

Finon, D., Pignon, V. and Gilotte, L. (2005). "Oligopolistic game around capacity expansion in liberalized electricity industries: The case of French market”. Working paper.

Ford, A (1999). “ Cycles in competitive electricity markets: A simulation study of the Western United States”. Energy Policy.

Friedman, J.W. (1977). “Oligopoly and the theory of game”. Amsterdam: North Holland.

Gabriel, S.A., Kiet, S., and Zhuang, J. (2005). “A mixed complementarity-based equilibrium model of natural gas markets". Operations Research, vol 53, 799-818.

Joskow, P.L. (2007). "Competitive electricity markets and investment in new generating capacity". In: The new energy paradigm, Dieter Helm, ed, Oxford University Press.

Murphy, F.H., Sherali, H.D., and Soyster, A.L. (1982). "A mathematical programming approach for determining oligopolistic market equilibrium". Mathematical Programming, vol 24, 92-106.

Murphy, F.H. and Smeers, Y. (2005). "Generation capacity expansion in imperfectly competitive restructured electricity markets". Operations Research, vol 53, no 4, 646-661.

Oren, S.S. (2004). "Ensuring generation adequacy in competitive electricity markets”, Electric Power Research Institute.

Papalexopoulos, A.D. (2004). "Supplying the generation to meet the demand", IEEE Power and Energy Magazine, vol 2 , no 4, 66-73.

Pérez-Arriaga, I. J. (2001). "Long-term reliability of generation in competitive wholesale markets; A critical review of issues and alternative options". IIT Working Paper IIT -00098IT.

Pineau, P.O. and Murto, P. (2003). "An oligopolistic investment model of the Finnish electricity market”. Annals of Operations Research, vol 121, 123-148.

Vázquez, C., Rivier, M. and Pérez-Arriaga, I. J. (2002). "A market approach to long-term security of supply”. IEEE Transactions on Power Systems, vol.17, 03.2, 349-357.

Ventoza, M., Denis, R. and Redondo, C. (2002). "Expansion planning in electricity markets. Two different approaches." Proceedings of the 14th Power Systems Computation Conference (PSCC), Seville. 
Von der Rehr, N.H.M. and Harbord, D. (1997). "Capacity investment and competition in decentralized electricity markets", Memorandum from Department of Economics, University of Oslo, No 27. 